\title{
Erratum to: Component and system reliability-based topology optimization using a single-loop method
}

\author{
Mariana Silva • Daniel A. Tortorelli • Julian A. Norato • \\ Christopher Ha $\cdot$ Ha-Rok Bae
}

Published online: 25 February 2010

(C) Springer-Verlag 2010

\section{Erratum to: Struct Multidisc Optim}

DOI 10.1007/s00158-009-0401-5

The original version of this article unfortunately contained mistake. The presentation of Figs. 4, 8, 12, 17, 18 and 19 were incorrect. The corrected figures are given below.
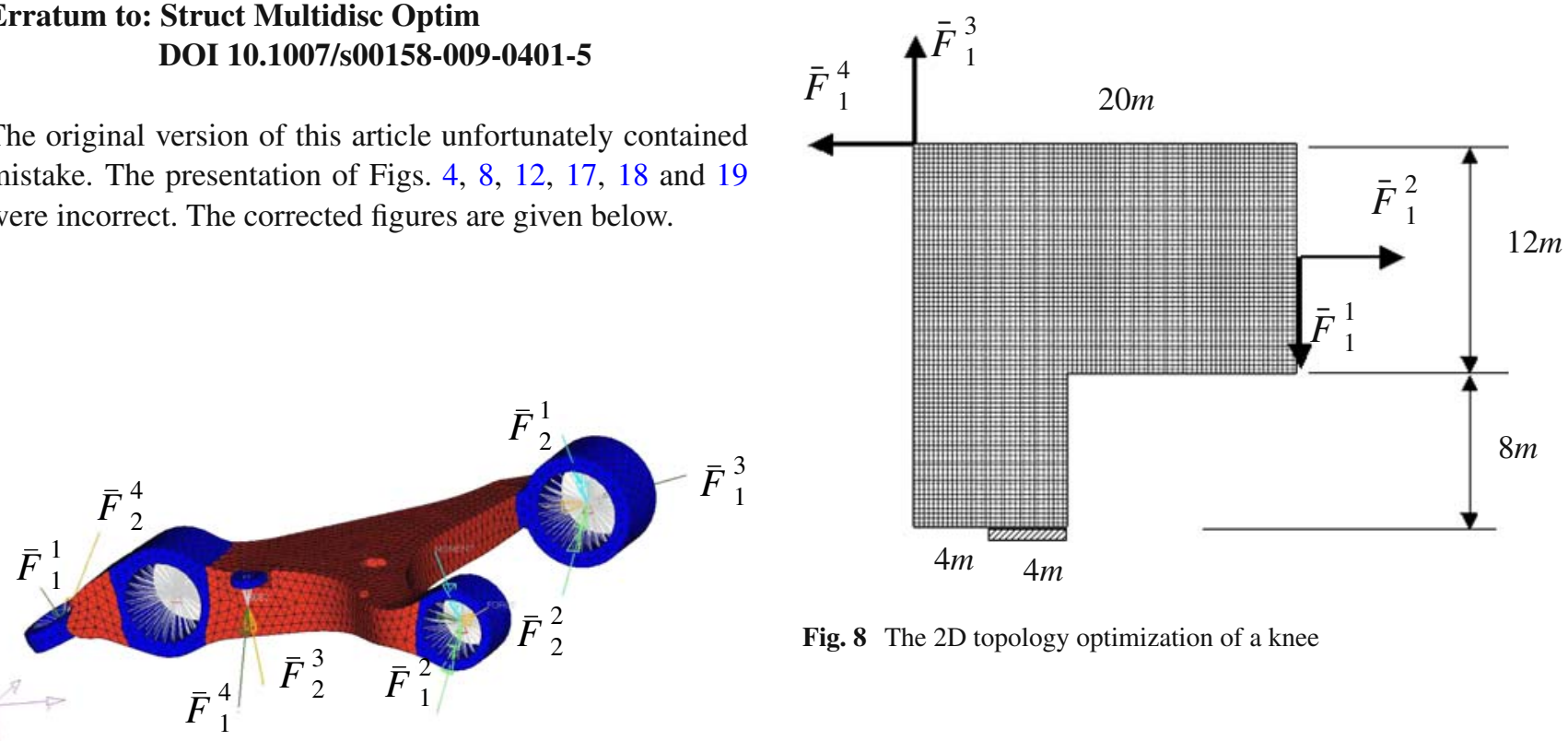

Fig. 8 The 2D topology optimization of a knee

Fig. 4 Topology optimization of an automotive control arm

The online version of the original article can be found at http://dx.doi.org/10.1007/s00158-009-0401-5.

M. Silva $(\varangle) \cdot$ D. A. Tortorelli

Department of Mechanical Science and Engineering,

University of Illinois at Urbana-Champaign,

1206 West Green St., Urbana, IL 61801, USA

e-mail: mfsilva@uiuc.edu

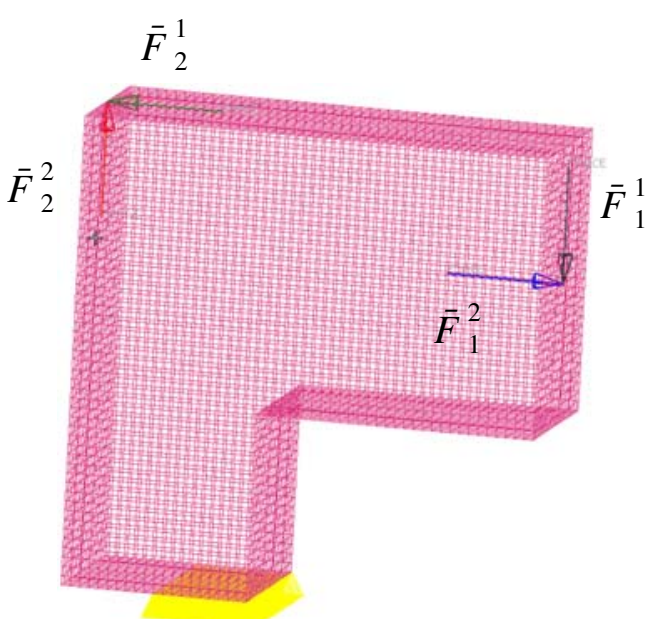

J. A. Norato - C. Ha · H.-R. Bae

Champaign Simulation Center, Caterpillar Inc.,

1901 S. First St., Champaign, IL 61820, USA

Fig. 12 Topology optimization of a knee 


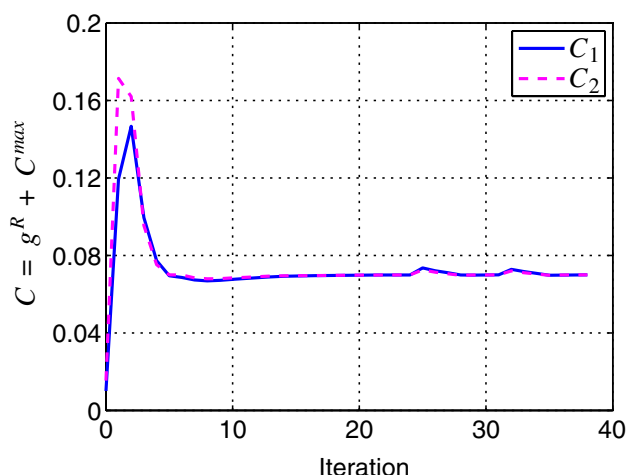

(a) CRBTO

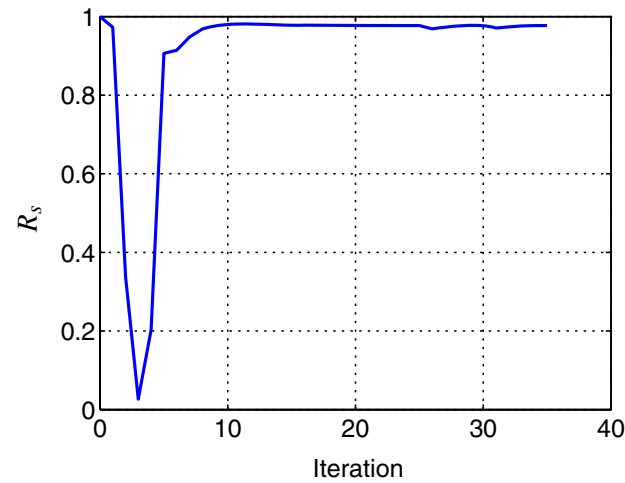

(b) SRBTO

Fig. 17 Constraint convergence for the knee problem $(\mathbf{a}, \mathbf{b})$

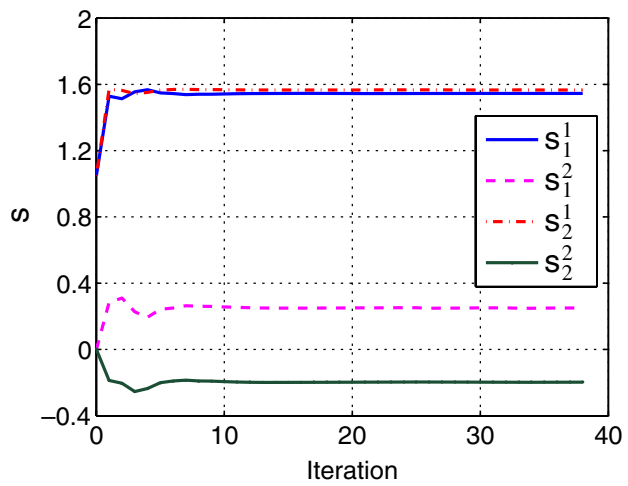

(a) CRBTO

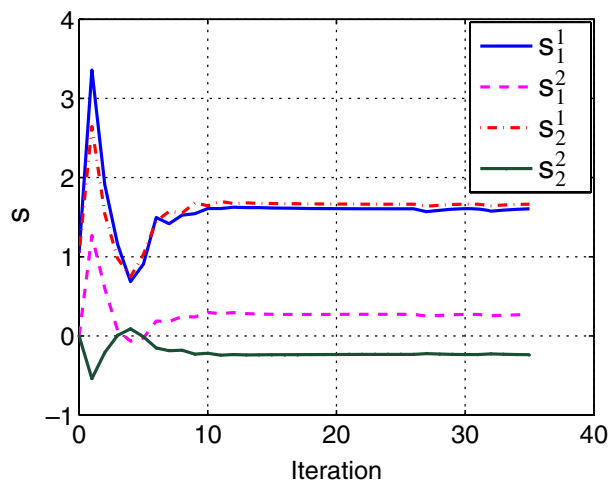

(b) SRBTO

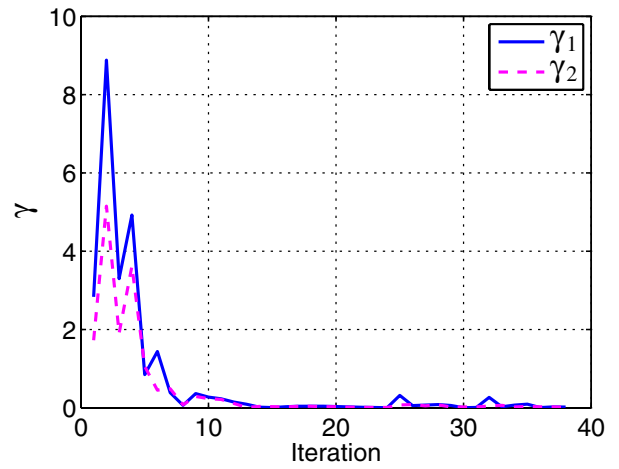

(a) CRBTO

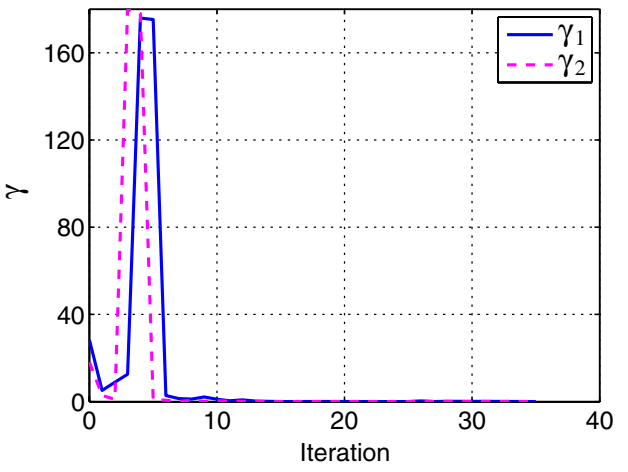

(b) SRBTO

Fig. $19 \gamma$ convergence for the knee problem $(\mathbf{a}, \mathbf{b})$ 